Open Access

\title{
Productivity growth in China's large industrial firms: patterns, causes, and implications
}

TU Zhengge ${ }^{*}$ and Shen Renjun

\author{
* Correspondence: \\ tuzhengge@163.com \\ School of Economics and Business \\ Administration, Central China \\ Normal University, 152 Luoyu Road, \\ Wuhan 430079, China
}

\begin{abstract}
Background: China's economy has experienced a high-rate growth since the reform and opening up in 1978. However, some macro-statistics indicated that China's economy grows with a low efficiency. In fact, these conclusions based on macrostatistics and the performance of the economy as a whole cannot reflect the multilevel, dynamic and, therefore, complicated situation of China. By using firm-level data, and the stochastic frontier production model, this paper makes an investigation on the changing trends of TFP of China's LMIE between 1995 and 2002, and the decomposition of factors of growth.

Results: Main findings include: (1) the weighted average of the annual growth of TFP in China's large and medium sized industrial enterprises was as high as $6.8 \%$ with a rising trend during 1996-2002; (2) the contribution to TFP growth by the factor of Frontier Technology Progress reached as much as 14 percentage points per annum on average; (3) the decline in Technical Efficiency (Relative to the Frontier) reduced the TFP growth by 7.1 percentage points per annum on average; (4) Allocative Efficiency contributed on average only 0.02 percentage points per annum to the TFP growth and Scale Dis-Economy slowed the growth of TFP by 0.33 percentage points per annum.

Conclusions: The results show that at the turn of the century, the most important part of China's industry was in the middle of an industrial productivity revolution driven by both Frontier Technological Progress and the great potential of technical efficiency of lagging enterprises. The revolution is driven by increased competition, privatization, foreign investment, and business expansion.
\end{abstract}

Keywords: Total factor productivity, Frontier technology progress, Technical efficiency, Scale economy, Allocative efficiency, Large and medium-sized industrial enterprises (LMIE)

\section{Background}

Over the two decades since its opening up to the world, the increase in Gross Domestic Product (GDP) of China keeps at a level between 8 and $9 \%$ per year. However, many economists point out that the high growth rate of China could not be attributed to the improvement of productivity, but to the high saving rate and massive capital input, including the inflow of foreign capital. Furthermore, some macro-statistics also indicated that China's economy grows with a low efficiency. For example, according to

(c) The Author(s). 2016 Open Access This article is distributed under the terms of the Creative Commons Attribution 4.0 International License (http://creativecommons.org/licenses/by/4.0/), which permits unrestricted use, distribution, and reproduction in any medium, provided you give appropriate credit to the original author(s) and the source, provide a link to the Creative Commons license, and indicate if changes were made. 
Standard \& Poor's statistics in 2004, the proportion of non-performing loan (NPL) in the four biggest state-owned banks was over $45 \%$, whilst the proportion of large and medium-sized industrial enterprises (LMIE) experienced a loss of more than $30 \%$. In fact, these conclusions based on macro-statistics and the performance of the economy as a whole are not able to reflect the multi-level, dynamic and, therefore, complicated situation of China. By using firm-level data, and the stochastic frontier production model, an investigation is conducted on the changing trends of total factor productivity (TFP) of China's LMIE from 1995 to 2002 as well as the decomposition of factors of growth. The added value of the investigated enterprise group accounted to $15-19 \%$ of China's total GDP between the year 1995 and 2002, and this percentage is still increasing. Hence, the empirical results here are of great importance to the further study of the dynamics of the industrial productivity progress in China, and of its potential as well.

The stochastic frontier production model was originally developed by [1, 11], and soon became popular in econometrics. In this model, we assume that some non-price factors such as organizing, management or institutional factors could lead to the loss of efficiency during the production process, and thus cannot reach the optimal frontier technology level. Nishimizu and Page [12] suggested decomposing TFP into the change of frontier technology and the change of relative frontier technology efficiency. Later on, lots of research has been done using this method to analyze the improvement in TFP. Bauer [2] used the data on the U.S. airline industry to decompose the TFP growth into the change in frontier technology progress, the change in technology efficiency relative to the frontier, and the improvement in scale economy. This approach was also applied to analysis on the TFP and frontier technology progress in the Organization for Economic Co-operation and Development (OECD) manufacturing industry [3]. Additionally, with the above model, decomposition of TFP of the Korean manufacturing industries and agriculture in all the provinces in China were studied [6-8], and the technical efficiency (TE) of the industrial sector of China were inspect $[15,16]$. Furtherly, the constant-scale-return non-parameter model was introduced in decomposing TFP growth rate by the DEA-Malmquist index method, using province data of China [4], and the effects of ownership on the productivity of China's manufacturing sector were interpreted based on the data of 1,036 super-sized industrial enterprises in 1993 [13]. Besides, Wu [14] employed the panel data of 27 provinces during 19811995, and studied the sustainable development problem of China through the decomposition of productivity.

The studies above use either national or provincial level macro panel data or the cross sectional firm level data. However, after data aggregation, a certain part of information of macro-data would be lost due to the substantial reduction in variation of the variables, and cross sectional data are not able to reveal the features of the dynamic change in productivity and technology efficiency. However, the years from 1994 to 2002 were exactly the crucial period of the transformation of China from a planned economy into a market economy, and industrial enterprises in China experienced significant dynamic changes. On the other hand, according to Schmidt and Sickles (1984), using cross sectional data to study TE will cause three major econometric problems in the stochastic frontier model: first, the estimation of the model relies highly on the error distribution assumption; second, the independent assumption is too strong; and the third and the biggest drawback of 
cross sectional data is that the estimation of TE lacks consistency. Using panel data will easily overcome these three obstacles. That's because, from the point of sampling theory, panel data are capable of being viewed as repeated sampling of massive samples. Compared to pure cross sectional data, panel data is not only richer in information, but also more importantly in reducing the inconsistency of TE estimation.

The literature that uses macro data in TFP study of Chinese economy is numerous. But in the field of Chinese productivity growth research, no literature using panel data at the firm level to estimate and decompose the TFP in Chinese industries is available. By using unbalanced panel data and stochastic frontier model, this paper studies the change in TFP of the LMIE in different industry sectors during 1995-2002. By following the analyzing method brought forward by Kumbhakar and Lovell [10], the increase in TFP is decomposed into four parts in the present work,: including frontier technology progress, change in relative frontier technology efficiency, elevation on resources allocation efficiency and improvement on scale efficiency.

The analytic framework of TFP improvement and the setup of stochastic frontier model are put forward in the second part of this work. The third part describes the data for empirical analysis and the definition of the variables followed by citation of the decomposition result of productivity improvement in the fourth one. The fifth part provides hypothesis tests for model specifications. The sixth part contains the conclusions and implications.

\section{Methods}

Decomposition of TFP and the stochastic frontier production model Decomposition of TFP

According to Kumbhakar [9], the decomposition of TFP is related to six concepts: total factor productivity (TFP), frontier technical progress (FTP), technical efficiency (TE), change rate of TE, allocative Efficiency (AE) and scale economy (SE). The aim of adding "frontier" is to emphasize the difference between frontier production function and average production function.

The relation among actual output, frontier output and TE can be expressed as:

$$
y_{i \tau}=f\left(x_{i \tau}, t\right) \exp \left(-u_{i \tau}\right)
$$

where $y_{i \tau}$ is the real output of enterprise $i(i=1, \ldots \ldots, \mathrm{N})$ in period $\tau(\tau=1, \ldots, \mathrm{T}) . x_{i \tau}$ is the vector of inputs. $f($.) is the fixed part of production frontier. $t$ is the time trend index that serves as a proxy for technical change; $u_{i l}>=0$, is the output-oriented technical inefficiency used to estimate the TE. In order to avoid the confusion between technological variable $\mathrm{t}$ and the subscript $\tau$ used to mark input-output period, in the following discussion, we omit the subscript $\tau$ and the subscript $\mathrm{i}$ to mark the enterprises, and only keep the subscript $\mathrm{j}$ of input factor, where $x_{j}$ stands for input $\mathrm{j}$.

Frontier technological progress (FTP) The production frontier function in logarithm, $\ln f($.), is partially differentiated with respect to time t to generate:

$$
\frac{d \ln f(x, t)}{d t}=\frac{\partial \ln f(x, t)}{\partial t}+\sum_{j} \frac{\partial \ln f(x, t)}{\partial x_{j} / x_{j}} \frac{d x_{j} / x_{j}}{d t}
$$

The first term of the right-hand part of Eq. 2, $\partial \ln f(x, t) / \partial t$, measures the change in 
output caused by FTP. The second term reflects the contribution of increase in input to output. Using the output elasticity expression of factor $\mathrm{j}, \varepsilon_{j}=\partial \ln f(x, t) / \partial \ln x_{j}$, the second term is rewritten as $\sum_{j} \varepsilon_{j} \dot{x}_{j}$, where $\dot{x}_{j}$ is the derivative of $x_{j}$ with respect to time. Define $\dot{x}_{j}=\partial \ln x_{j} / \partial t$, Eq. 2 is transformed into:

$$
\frac{d \ln f(x, t)}{d t}=F T P+\sum_{j} \varepsilon_{j} \dot{x}_{j}
$$

TE and its change rate $(T \dot{E})$ TE is technical efficiency, and it measures the gap between one enterprise's actual output and the maximum potential output under fixed input.

Defining the growth rate of output as: $\dot{y}=d \ln y / d t$, both sides of equation (1) are taken logs of and then partially differentiated with respect to the trend variable t. Using equation (3), the growth rate of output into FTP, increase in input and improvement of technical efficiency $(T \dot{E} \cdot)$ are decomposed.

$$
\dot{y}=\frac{d \ln f(x, t)}{d t}-\frac{d u}{d t}=F T P+\sum_{j} \varepsilon_{j} \dot{x}_{j}-\frac{d u}{d t}
$$

Define the rate of change in TE denoted by $\dot{T} E$ as $-d u / d t$, which can be interpreted as the rate at which an inefficient producer catches up with the production frontier.

The growth rate of TFP $(T \dot{F} P)$ Using the growth accounting method, the growth in TFP is calculated as:

$$
T \dot{F} P=\dot{y}-\sum_{j} S_{j} \dot{x}_{j}
$$

where $\mathrm{SB}_{\mathrm{jB}}$ is the share of input's $\mathrm{j}$ in production cost with $\sum_{j} S_{j}=1$. Under the profit maximizing conditions, the output elasticity of one unit of input should equal to the cost share of that factor, and this is the theoretical foundation of using growth accounting method to calculate total factor productivity growth. In reality, output elasticity of a factor may not equal to its cost share, due to allocative inefficiency.

Allocative efficiency (AE) and Scale efficiency (SE) By substituting equation (4) into equation (5), equation (5) is rewritten as:

$$
\begin{aligned}
T \dot{F} P & =F T P-\frac{d u}{d t}+\sum\left(\varepsilon_{j}-S_{j}\right) \dot{x}_{j} \\
& =F T P-\frac{d u}{d t}+\sum_{j}\left(\lambda_{j}-S_{j}\right) \dot{x}_{j}+(R T S-1) \sum_{j} \lambda_{j} \dot{x}_{j}
\end{aligned}
$$

where, $\lambda_{j}=\varepsilon_{j} / \sum_{j} \varepsilon_{j}=\varepsilon_{j} / R T S$ is the relative output elasticity of the input factor $j$ in the frontier production function, with $\Sigma_{j} \lambda_{j}=1$. The transformation is to make relative output elasticity $\lambda_{j}$ comparable to relative cost share $S_{j}$, so as to calculate AE. RTS $=\sum_{j} \varepsilon_{j}$, indicating the total return of scale. The last two terms of equation (6) measure the two main effects of factors on the growth in productivity: 
Allocation efficiency, $A E=\sum_{j}\left(\lambda_{j}-S_{j}\right) \dot{x}_{j}$, denotes the contribution of change in input factor distribution to the growth in productivity, and Scale efficiency, $S E=(R T S-1)$ $\sum_{j} \lambda_{j} \dot{x}_{j}$, denotes the contribution of return to scale to the growth in productivity. Return to scale refers to the proportion of output growth that is greater than the incremental of input, given other conditions.

To sum up, the TFP growth in equation (6) is able to be decomposed into FTP, increase in TE, AE, and SE.

\section{Specification of stochastic frontier production model}

Using the parameters estimated from the stochastic frontier production model, it's capable to decompose TFP growth. Stochastic frontier production model requires considering not only FTP, but also the interaction effects between FTP and input factors, technical inefficiency relative to the frontier and the substitution effects among different input factors on production. Therefore, the trans log stochastic frontier production function is employed with time-varying technical inefficiency:

$$
\begin{aligned}
& \ln y_{i \tau}= \alpha_{0}+\sum_{j} \alpha_{j} \ln x_{j i \tau}+\alpha_{T} t+\frac{1}{2} \sum_{j} \sum_{l} \beta_{j l} \ln x_{l i \tau} \ln x_{j i \tau}+\frac{1}{2} \beta_{T T} t^{2} \\
&+\sum_{j} \beta_{T j} t \ln x_{j i \tau}+v_{i \tau}-u_{i \tau}, \\
& \mathrm{j}, \mathrm{l}=\mathrm{L}, \mathrm{k},
\end{aligned}
$$

where $y_{i \tau}$ is the observed actual output, $t$ is trend variables; $\mathrm{x}$ is input, subscripts $j$ and $l$ indicates the input type $(j=\mathrm{L}, \mathrm{K} ; l=\mathrm{L}, \mathrm{K})$. The error term, $u_{i n}$, represents production loss due to firm-specific technical inefficiency (unobservable). Thus, the error term is always greater than or equal to zero, and is assumed to be independent of the stochastic error, $v_{i t}$, which is assumed to be independently and identically distributed as $N\left(0, \sigma_{v}^{2}\right)$.

Following Battese and Coelli (1992), technical inefficiency is assumed to be defined by:

$$
u_{i \tau}=u_{i} \exp [-\eta(t-T)]
$$

where the distribution of $u_{i \tau}$ is taken to be the non-negative truncation of the normal distribution, $N\left(\mu, \sigma_{u}^{2}\right)$, and parameter $\eta$ denotes the rate of change of the technical inefficiency. A positive value $(\eta>0)$ is associated with the improvement of firm's technical efficiency over time.

Parameters in the stochastic frontier production model (7) and time-varying technical inefficiency index model (8) are jointly identified with maximum likelihood estimation using the program, FRONTIER4.1, in which the variance parameter is specified as $\gamma=\sigma_{u}^{2} / \sigma_{s}^{2}, \sigma_{s}^{2}=\sigma_{u}^{2}+\sigma_{v}^{2}$.

The technical efficiency level of firm $i$ at time $t\left(T E_{i t}\right)$ is defined as the ratio of the actual output to the potential output. With the composite errors separating method (JLMS for short) advanced by Jondrow et al. [5], the technical inefficiency $u_{i \tau}$ is separated from the composite error $v_{i \tau}-u_{i \tau}$ as,

$$
T E_{i \tau}=\exp \left(-u_{i \tau}\right)
$$

Using the stochastic frontier production model and the dynamic form of the technical inefficiency, frontier technology progress of firm $i$ is estimated at $t$ time, the change of technical efficiency, scale economy, and the allocative efficiency. 
According to the definition of the change in TE, $u_{i \tau}=u_{i}{ }^{*} \exp [-\eta(t-T)]$, the change of the technical efficiency is derived as:

$$
\dot{T} E_{i \tau}=-\partial u_{i \tau} / \partial t=\eta \cdot u_{i} \exp [-\eta(t-T)]=\eta \cdot u_{i \tau}
$$

Obviously, the change of the technical efficiency is related not only to the parameter $\eta$ which is the rate of change of the industrial technical inefficiency, but also to firmspecific technical inefficiency $u_{i \tau}$.

The output elasticity in the frontier production function ought to be estimated before assessing the contribution of the improvement in scale economy to the growth of TFP. In the stochastic frontier productive function model (7), the output elasticity of factor $j$ (capital $\mathrm{K}$ or Labor $\mathrm{L}$ ) is calculated as:

$$
\varepsilon_{j}=\partial \ln f(x, t) / \partial \ln x_{j}=\alpha_{j}+\frac{1}{2} \sum_{l \neq j} \beta_{j l} \ln x_{l}+\beta_{j j} \ln x_{j}+\beta_{T j} t, \quad \mathrm{j}, \mathrm{l}=\mathrm{L}, \mathrm{K} .
$$

The aggregate return to scale measure $\mathrm{RTS}=\sum_{j} \varepsilon_{j}$, $\mathrm{RTS}<1,=1$ or $>1$ represents the return to scale is decreasing, constant or increasing, respectively. Consequently, the contribution of scale economy SE to TFP growth is:

$$
S E=(R T S-1)\left(\lambda_{k} * \dot{k}+\lambda_{l} * \dot{i}\right)
$$

$\dot{k}, \dot{l}$ denotes the growth rate of the capital and labor factor, respectively.

Based on the output elasticity and the cost share of inputs, the contribution to TFP growth by allocative efficiency is calculated as:

$$
A E=\left(\lambda_{k}-S_{k}\right) * \dot{k}+\left(\lambda_{l}-S_{l}\right) * l
$$

According to the stochastic frontier production function model (7) and the definition of the frontier technology progress, the contribution of frontier technology progress to the TFP growth (i.e., the growth of output directly) is:

$$
F T P=\partial \ln f(x, t) / \partial t=\alpha_{T}+\beta_{T T} t+\sum_{j} \beta_{T j} \ln x_{j}, \mathrm{j}=\mathrm{L}, \mathrm{K} .
$$

\section{Data and variables definition}

\section{Data}

This paper uses firm-level annual survey data of China's LMIE during 1995-2002. The data set contains 22,000 firms each year and is collected and maintained by the National Bureau of Statistics (NBS). The firm-level panel data set allow us to analyze the dynamics of TFP growth, and identify the source of economy growth.

Observations with either missing variables or negative values are dropped from the data set. In sum, there is 21,000 enterprises per year and a total of 177,086 observations over the eight years from 1998 to 2005.

The LMIE plays a very important role not only in the manufacturing sector but also in the whole economy. The number of LMIE accounts for about $12 \%$ of all the stateowned enterprises and the non state-owned ones whose annual production value is above 5 million Yuan; it employs $16.7 \%$ of the whole labor force in the manufacturing sector while contributes above $40 \%$ of the added value; and it makes about $15 \%$ to 
$19 \%$ of the whole country's GDP. Hence, the productivity level of LMIE not only represents China's leading productivity but also determines the efficiency level of China's industry and even the whole economy as our research objects.

Price factor is a challenge confronted when studying productivity. During the period of 1995-2002 China's retail price did not fluctuate very much. Still, the differences of the output prices and input factors between different industries should not be ignored. In general, prices of energy and raw materials have increased while manufacturing products' prices have deceased. The industry added value and the price of net value of fixed assets are shown in the appendix.

\section{Definition of variables}

Of the main variables in the model (7), the output variable $y_{i \tau}$ is the industrial addedvalue deflated by price index, while the variable of factor $x_{k}$ is the real net value of fixed assets, and $x_{l}$ is the number of labor being employed one year on average. The variable t equals $1,2, \ldots .8$, is the time corresponding to the years from 1995 to 2002. When calculating the total factor productivity's growth using the growth accounting method, we use the labor and assets' average cost share of each industry. The costs of labor primarily include wages, bonus, labor welfare, and labor insurance expenditure. The costs of capital mainly include interest expenditure and depreciation of fixed asset in the current year. The calculation methods of the average rate of increment of the industrial output and input factors, and the industrial average cost share of labor and assets $\left(S_{l}\right.$ $S_{k}$ ), are found in the appendix.

In the condition of non-neutral technology stochastic frontier production function, the output elasticity of input factor and frontier technology progress is related to the input level. Thus, when evaluating the industrial sector's change rate of TFP, FTP, SE, $\mathrm{AE}$, the input factor $(\ln k, \ln l)$ and the cost share of factors are all taken by average annual values of the industry.

\section{Hypothesis test for model specifications}

The correctness of the specifications of the stochastic frontier production model would directly affect the accuracy of the conclusion. Traditional TFP model mostly uses the Cobb-Douglas production function which is simple in its form and neither distinguishes the stochastic noise and technology improvement, nor takes technical inefficiency into consideration. Because of these, the model is tested specifically in five dimensions: (1) the applicability of the stochastic frontier model; (2) the time-varying of the technical efficiency relative to the frontier; (3) whether the frontier technology progress exists; (4) Whether or not technology is neutral; (5) whether to use the simple Cobb-Douglas or the stochastic frontier production function.

Five examinations are carried out in this paper on the specifications of the stochastic frontier production model based on the statistic likelihood ratio (LR) (Table 1). The logarithm of the statistic likelihood ratio $\lambda$ :

$$
\lambda=-2\left[L\left(H_{0}\right)-L\left(H_{1}\right)\right]
$$

$L\left(H_{0}\right)$, and $L\left(H_{1}\right)$ denote respective values of logarithmic likelihood function under the specification of null and alternative hypothesis. Under the null hypothesis, the statistic $\lambda$ has approximately a Chi-square distribution (or mixed Chi-square distribution) with degrees of freedom equal to the number of restrictions. 
Table 1 The results of hypothesis testing (total simple)

\begin{tabular}{lllll}
\hline The null hypothesis $H_{0}$ & $L\left(H_{0}\right)$ & $\lambda$ & $C V$ & the testing results \\
\hline 1. $H_{0}: \gamma=\mu=\eta=0$ & -232143 & 71496 & $10.5^{\text {a }}$ & reject $H_{0}$ \\
2. $H_{0}: \eta=0$ & -196828 & 866 & 6.6 & reject $H_{0}$ \\
3. $H_{0}: a_{T}=\beta_{T T}=\beta_{T L}=\beta_{T K}=0$ & -197866 & 2942 & 13.28 & reject $H_{0}$ \\
4. $H_{0}: \beta_{T K}=\beta_{T L}=0$ & -196442 & 94 & 9.21 & reject $H_{0}$ \\
5. $H_{0}: \beta_{K K}=\beta_{L L}=\beta_{L K}=\beta_{T T}=0$ & -198111 & 3432 & 13.28 & reject $H_{0}$ \\
\hline
\end{tabular}

Notes: The non-constraint value of log likelihood $L R=-196395$. The five null Hypothesis $\left(\mathrm{HB}_{\mathrm{OB}}\right)$ are all rejected at the significant level of $1 \%$. ${ }^{a}$ the critical value for this test involving $\gamma=0$ comes from Table 1 of Kodde, Palm (1986, p. 1246)

For space limitation, the tests of hypotheses are given for total sample more than by industry. Traditional research of productivity used average production function (the elasticity of output with respect to factors is average) to measure productivity, but the production function ignored the influence due to technical inefficiency on production. If the technical inefficiency does not exist, the estimation becomes a simple OLS estimation. There is no stochastic frontier parameter in the model, and the stochastic frontier model becomes an average production model. Therefore, the null hypothesis $H_{0}: \gamma=\mu=\eta=0$ is examined. If the null hypothesis holds, and then technical inefficiency does not exist. The resulting statistics rejects the null hypothesis at significant level of $\alpha=1 \%$, which suggests that compared with the stochastic frontier production function, the average production function is an inadequate representation of LMIE in China, and underestimates the actual frontier because of technical inefficiency effects.

The second null hypothesis, that technical inefficiency is time-invariant $\left(\mathrm{H}_{0}: \eta=0\right)$, is also rejected at the $1 \%$ significant level for the total sample. This means the technical efficiency in China's LMIE during year 1995-2002 is time varying, given the stochastic frontier model defined by equation (8).

The third null hypothesis, that there is no technical progress $\left(H_{0}: \alpha_{T}=\beta_{T T}=\beta_{T L}\right.$ $\left.=\beta_{T K}=0\right)$, and the fourth null hypothesis, that technical progress is neutral $\left(H_{0}: \beta_{T K}\right.$ $\left.=\beta_{T L}=0\right)$, are both rejected at the $1 \%$ significant level for the total sample. This implies that non-neutral technical progress in China's LMIE exists.

The last null hypothesis, that the technology in China's LMIE is a Cobb-Douglas $\left(H_{0}\right.$ : $\beta_{K K}=\beta_{L L}=\beta_{L K}=\beta_{T T}=0$ ), is also rejected at the $1 \%$ significant level for the total sample. Thus, the Cobb-Douglas production function is not an adequate specification for China's LMIE, given the assumptions of the trans log stochastic frontier production function model.

All results of the test show that the trans log stochastic frontier production model with non-neutral technology and time-varying technical inefficiency is really better than other models.

\section{Results}

\section{Main empirical results}

Stochastic frontier production models are estimated individually for each of the 37 two-digital industries, and then the TFP growth, FTP, change rate of TE, AE and SE are calculated for all the industries during the period 1995-2002. 


\section{Dynamics of TFP growth}

How to calculate the growth rate of TFP by using the growth accounting method is already described above. TFP growth is made out with the industry growth rate of added-value, labor and net value of fixed asset. Deflating the price factor, the average annual growth rate of industry added-value for all China's LMIE reaches as much as $11.5 \%$ during the years 1996-2002, which was close to the growth rate for all industrial firms announced by the National Bureau of Statistics. Capital stock's average annual growth rate come up as much as $12.3 \%$, and the total number of labor employed decreases at a rate of $4.4 \%$ yearly. The industry added-value was taken as the weight in calculating the average values for all variables involved.

The LMIE' rate of increment of TFP during the years 1996-2002 was an average of $6.8 \%$ per year. It decreased by $4.3 \%$ in the year 1996, and $0.7 \%$ in 1997, and then it grows at an accelerated speed. And it was 3.0, 7.5, 11.2, 8.2, and $14.0 \%$, respectively, during the 1998-2002 periods.

Among all the industries during these years, the five industries which had the most rapid average annual rate of increment of TFP are: transport equipment manufacturing, with $17.8 \%$, instrument manufacturing, with $16.0 \%$, Print, with $13.8 \%$, metal manufacturing, with $13.6 \%$, medicine manufacturing, with $12.4 \%$; and the five slowest industries are: petroleum processing, with $-4.6 \%$, electric power industry, with $-4.1 \%$, tap water industry, with $-4.0 \%$, chemical fiber \& textile manufacturing, with $2.1 \%$, petroleum \& natural gas industry, with $2.3 \%$. It's shown that the industries facing high extent of opening-up and intense competition have a high rate of increment of TFP. In the opposite, the industries with high degree of monopoly and low degree of opening-up have a low rate of increment of TFP, even a negative one.

In general, LMIE' increment of productivity in China decreased initially and then increased, and was increasing yearly as a whole during the years 1996-2002. The largescale investment in the years 1995-1997 did not brought high benefit, which was affected by the financial crisis and macro-control, and the TFP decreased in both the two years. After 1998, the productivity increased rapidly as well as the whole Asian economy's recovery.

\section{Frontier technological progress}

FTP means the extra rate of increment of the frontier output through the technical improvement without adding any input, and it directly affects the improvement of the TFP. Viewing from the mathematic formula representing the contribution of the FTP to the productivity, this contribution of FTP is not related to the level of the factor input, but related to the time $t$.

On the whole, the FTP during the years 1995-2002 sped up, and FTP of China's LMIE in 37 industries made an average annual contribution of $14 \%$ to the TFP. FTP made TFP grow fast mainly after the year 1998. FTP made TFP grow by $9.0 \%$ in the year $1998,12.3 \%$ in $1999,15.3 \%$ in $2000,18.9 \%$ in 2001 , and $22.6 \%$ in 2002 . The detailed data are available in the appendix.

The five industries, whose FTP made the greatest contribution to their TFP, were: telecommunications facilities industry, with $26.3 \%$, ferrous metal smelting processing, with $24.4 \%$, transport equipment manufacturing, $23.0 \%$, medicine manufacturing, $22.7 \%$, food manufacturing, $21.5 \%$. And the five industries which had the slowest 
improvement of FTP to TFP are: gas production and supply industry, with $2.85 \%$, tap water industry, with $2.4 \%$, petroleum processing, with $1.4 \%$, petroleum \& natural gas, $0.98 \%$, electric power industry, $0.17 \%$.

How to understand the effect of FTP in these China's LMIE? The stochastic frontier production function represents the industrial best technical structure in terms of the input and output, so the contribution made by the FTP here is the increment of the TFP in the best performance firms, and the figure is far higher than that of the average firms that are departures from the frontier and has technical inefficiency relative to the frontier, inefficient $\mathrm{AE}$ and diseconomies of scale. While in actual fact, many enterprises are under the frontier.

What is the real driving force behind the FTP? In the stochastic frontier production function, time $t$ is a variable used for the weight of the technical change, and time is also a variable that can hold everything. This means the technology used here has a very broad content, it includes not only direct technical factors, such as advanced technologies, patents, technical innovation, high-tech equipment and talented personnel, but also economic circles, but also non-technical factors such as economy, society, vicissitude of legal institutions, which refers to the development of private enterprises, the reform of state-owned enterprises, reform of tax system, foreign investment, and joining WTO, etc. These factors have a deep impact on the output and productivity. Our main purpose here is to verify the huge contribution made by FTP to the increment of China's enterprises' productivity, while it's hard to analyze in depth the factors behind the FTP in such a length-limited article. Still, four factors are concluded for further statistical analysis.

First, the intense competitions among the enterprises in the same industry are the driving force for FTP. As the reform toward the market economy progresses in China, the whole economy changes from the shortage economy to excessive supply, and the tariff protection gradually decreases, while the market competition becomes more intense. All of these make the enterprises adopting advanced techniques and invest more money on technologies, so as to keep a favorable position in the market competition. Intensive competitions advance greatly the industrial FTP. The 37 industrial sectors with slow FTP such as gas, tap water, electric power, petroleum processing and exploitation, are all highly monopolized by the state, and are all lack of competitions. While the industries with FTP having significant contribution to the growth of TFP, such as telecommunications facilities, food production, food processing, pharmacy, are all with a high degree of opening-up and competition.

Second, globalization and foreign direct investment are the sources of FTP growth. Accession to WTO provides China's enterprises a broad market prospect, thus, more advanced technologies and a better product quality are required. At the same time, the foreign manufacturers' entry into China's market has accelerated the pace of technology adaptation and update. Of all the LMIE, the number of foreign-invested enterprises reached 2935 in the year 2002 which is about 3 times the number in the year 1995, which were about 1,000. And the number of those invested by manufacturers from Taiwan, Hong Kong and Macao was 2495 in 2002, compared with 936 in the year 1995.

Third, the reform of ownership is an internal driving force of FTP. Clear property rights ensure the rewards to technical innovation and this is an interior driving force of 
FTP. The structure of ownership of the LMIE has changed a lot in the years during 1995-2002. The number of private enterprises reached to 1302 in 2002, which was only 5 in 1995; the number of mixed-owned enterprises reached 6135 from 1233; the proportion of foreign-invested enterprises including those invested by Taiwan, Hong Kong and Macao increased about two times than that in 1995, while the state-owned enterprises' number decreased from 15,361 to 7,215, and the number of collective-owned ones from 4008 to 2138 . These are of the institution reform factor of the increment of FTP.

Fourth, the expansion of the economy brings a better external environment for FTP improvement. The recovery of economy will bring huge demand,enabling enterprises to make huge output with limited input thereby improving productivity significantly. In contrast, in a contracted economy, the demand decreases dramatically, and the output will reduce consequently so does the employment rate and assets, especially the fixed assets. As a result, the productivity will remarkably decrease. During the years 1996 to 2002, the growth rate of China's GDP kept at about $8 \%$, and the whole society's fixed assets investment ratio kept at above $10 \%$ except for two years. So, the expansion period of economy in the years 1996 to 2002 undoubtedly made a favorable external environment for FTP.

\section{Technical efficiency (TE) and its rate of change}

Technical efficiency relative to the frontier is the ratio of the enterprise's actual output to the frontier output. The rate of change of Technical efficiency relative to the frontier $\dot{T} E$ is one important factor which makes the productivity change. With the results of the estimation on the 37 industries in the stochastic frontier production function model, each industry's TE and $\dot{T} E$ are obtained. The average industry value of TE is weighed by industry added-value, too.

First the average industry value of TE is generated according to the estimation of every enterprise's TE followed by acquisition of the average TE of all the LMIE. The results exhibit that the average TE of all the LMIE was just $31 \%$ in the years 1996 to 2002, which is the average ratio of real output to the optimal stochastic output level. TE in the years 1996 to 2002 is 32, 32, 32, 31, 30, 30 and $29 \%$ respectively, which means that TE is below one third on average and has been decreasing.

In view of different industries, the industries with the highest average annual TE in the years 1996 to 2002 are: tobacco industry with $55 \%$, ferrous metals mining and dressing with $51 \%$, paper manufacturing $46 \%$, nonferrous minerals smelting processing industry with $45 \%$, textile industry with $44 \%$; and the industries with the lowest average annual TE are: telecommunications facilities manufacturing with $12 \%$, instruments industry with $15 \%$, electric machine industry with $16 \%$, gas produce and supply industry with $17 \%$, arts \& crafts and other manufacturing industry $18 \%$. As for TE distribution, traditional industries (such as mineral, textile, paper manufacturing), high monopolized industries (such as tobacco industry) have higher TE than machine, electronic, and instruments industries. How to explain it?

It's seen from the definition of TE and the calculation method of the average industry TE that an enterprise's technical efficiency relative to the frontier level depends on the industrial frontier technical level, viz. the benchmarks level. Production frontier is the set of the maximum output which is corresponding to various sets of input factors. If 
the degree of the industrial technical creation and introduction has been enhanced, then the industrial frontier output level will greatly increase and the frontier production will greatly move up. If the technical innovation and adoption are limited to a few enterprises, and most firms are far from the production frontier, the average industry technical efficiency will not be high; on the contrary, if the technical innovation and FTP are not very remarkable, like some traditional industries, which has mature and stable technologies and whose production frontier does not change much, and whose technologies are pervasive in the industry, then most enterprise in the industry will have an output approaching the production frontier, and these industries have a higher TE compared with the new industries.

In addition, the weight influences the industrial average TE. If the very large enterprises in the industry have very low TE, then the usage of relative size firms as a weight will decrease the average industry TE. So the industrial FTP is considered as well as the industry structure to explain the industrial TE level. Therefore, it's not difficult to understand that some industry with a high technique does not have high TE.

With China's reform and opening-up, huge Multinational Corporations' entry will undoubtedly increase the difference of technology level among enterprises in each industry as well as technical efficiency among different enterprises, and decrease the industrial average TE level. On the other hand, the increasing technical differences among enterprises in different regions are another reason for the low TE level. It is an important character of our LMIE nowadays that there are huge differences of TE. And this reflects a problem that many enterprises face the pressure of market competition. But in view of the whole economy's development, the differences will be the potential sources of enhancing the overall technology level. That's another reason why we believe that China's industrial productivity is coming into a modernization reform.

In the analytic framework of frontier production function, we are concerned more about the change of TE's influence to the productivity. According to the frontier production function model, the change in TE determines the change in one firm's enterprise's technical efficiency.

This article aims to analyze the TE change in terms of the industries' average trend. The change in TE and its influence on productivity are expressed by the weighted average of enterprises' TE. The decline in TE of 37 industrial sectors lessened the productivity by 7.1 percentage points per year during 1996-2002. From -6.2 \% in 1996 to $-7.9 \%$ in 2002, the average TE was obviously characterized by a sharp falling trend. Of these 37 industrial sectors, only the tap water industries' TE got slightly better with an increase of $0.7 \%$; the decrease of TE was $0.4 \%$ per year in power industry, $2.3 \%$ in non-metal mining industry, $2.5 \%$ in tobacco industry, $2.6 \%$ in gas production industry; the top five industries with the greatest decrease of TE were chemical material industries with $11.1 \%$ per year, food production industries with $11.1 \%$, beverage industry with $11.6 \%$, rubber industry with $12.1 \%$ and electronics and telecommunication equipment manufacturing industry with $15 \%$.

Monopolistic industries were surprisingly characterized by low decrease in TE, while intensively competitive industries with large sum of foreign investment were characterized by rapid decrease in TE, such as food processing industry, food producing industry, electronics and telecommunication industry. What do the dynamic characteristics imply? Electronics and telecommunication industry, food industry are characterized by 
an increasingly intensive competition; new technology, manage experiences and techniques learned from foreign enterprises have promoted the industrial production frontier at the same time broadening the TE gaps between the frontier technology and a firm's actual production, which may decrease the average TE relative to frontier. From a policy perspective, the low TE implies that it is possible to increase TE by market choosing and emulating along with learning from, catching up with and helping each other, which means that the potential of productivity revolution exists. The crucial factors which determine the gap of TE are further elaborated in terms of the ownership structure change, technological spillover, and industrial competition situation, firm's size in the sixth part.

\section{Allocative efficiency}

Optimizing allocation of production factors will bring about higher productivity. The cost and marginal output of production factors varies across firms in every industry. If a factor is with higher cost but lower marginal income, the rapid growth of this factor in an industry will consequently cause the decline in productivity of enterprises and of the industry on average; conversely, the decrease of this factor will promote productivity, which is defined as the allocative efficiency of resources. Free flow of labor and capital makes the rise of resource allocative efficiency possible. From the macro-economy perspective, along with the deepening of the Chinese market-oriented economy reform, the rise of the social resources allocative efficiency became the main contribution factor to the rapid development of Chinese economy. The research of this article mainly targeted at the enterprises in an industry and analyzed the allocative efficiency of input factors from the enterprises aspect. Inter industry comparison is not studied in this paper.

On average, the growth of productivity caused by the rise of the AE, which contributed to TFP only by $0.14 \%$ per year during 1996-2002, was not significant in all 37 industrial sectors. During this period, the contributions to productivity by AE are 0.15 , $0.34,0.05,0.26,0.16,-0.14$ and 0.15 percentage points a year on average, respectively.

From the dimension of industries, during 1996-2002 the rises of productivity due to the improvement of $\mathrm{AE}$ were respectively $4.44 \%$ per year on average in petroleum and natural-gas extraction industry, $3.97 \%$ in printing industry, $3.0 \%$ in ferrous mining industry, $2.063 \%$ in gas production industry and $1.99 \%$ in instruments industry; the fall of productivity caused by ineffective allocation of resources are respectively $1.52 \%$ per year on average in paper-making industry, $1.75 \%$ in ferrous melting industry, $1.87 \%$ in beverage industry, and $2.23 \% \mathrm{~s}$ in petroleum processing industry, $2.38 \% \mathrm{~s}$ in power industry. In most of other industries, the contribution of resource AE to the productivity was extremely low. Moreover, AE has contributed almost zero to TFP among all the LMIEs. Is this a good phenomenon or an ill omen? How to explain?

If the capital and labor flow freely, production factors will seek the highest return and enterprises will also maximize their profit by selecting the optimal combination of production factors. Under the circumstance of perfect competition, the equilibrium condition for maximum profit is that the marginal cost of a factor equals to its price (cost). Under this scenario, the contribution of $\mathrm{AE}$ to the productivity will come to zero. In reality, as far as a certain enterprise or industries is concerned, the equilibrium condition is hardly satisfied and the AE may be positive or negative for varies reasons,. However, when we calculating the average contribution of all the enterprises in an industry with industrial value added as the weight, the positive and negative values will offset each other, which 
imply that the growth of productivity attributed to the efficiency of resource allocation would be nearly zero. This result tells us that the marketization of Chinese economy has been improving greatly and the function of market in allocating resources has been enforced; overall on average, the potentiality to promote the productivity by optimizing the efficiency of resource allocation may not be great, nevertheless, at the firm level, as to some industries and enterprises, there is still potential to promote the AE.

\section{Return to scale and scale economy}

The industrial frontier production function estimated the return to scale and the scale efficiency in terms of the mean value of industrial input factors, therefore, the return to scale and scale efficiency we discussed represented the average situation of an industry. The index of return to scale is the sum of the elasticity of factors in-put $\left(\varepsilon_{l}, \varepsilon_{k}\right)$. If the RTS is more than one, it means that after controlling the technical progress and the technology inefficiency, an enterprise still enjoys the scale efficiency by enlarging the scale which means that the ratio of production growth is higher than that of in-put factor growth. The calculation showed that the return to scale was on average 0.903 for LMIEs in all the 37 industries. In these 37 industries, only the tobacco industry enjoyed the return to scale of 1.42 on average and the tap water enjoyed 1.033, just more than one, which illustrated the efficiency of larger enterprises was higher given the marginal efficiency of capital and labor (that is the production elasticity of factor input). The return to scale in garment industry, petroleum and natural-gas extraction industry and petroleum processing was near to one. However, the return of scale in other industries were much less than one, with 0.739 in nonferrous melting industry, 0.731 in chemical material and products industry, 0.715 in instrument industry, 0.708 in timber industry, and 0.657 in gas product and supply industry, respectively, which indicated that the efficiency was lower in larger enterprises given the production elasticity of factors. The ownership of these large and super large enterprises mainly belonged to the state, suggesting that the inefficiency of state-owned enterprises may be one of the reasons why the return to scale was small than one in lots of industries.

The contribution of scale economy to productivity depends on two factors: the index of return to scale and the composite index of inputs growth. If the return to scale (RTS) is constant, RTS equal to one, change of the scale has no effect on productivity. However, the variation of scale may have an effect on productivity; no matter the return to scale is more than one or less than one. The ultimate outcome depends on the index of the composite index of inputs growth. When the RTS is larger than one, the expansion of scale will increase the productivity and the reduction of scale will decrease the productivity; when the RTS is less than one, the results are the opposite.

From the industry point of view, during 1996-2002 the top-five industries with average annual improvements of productivity resulted from the scale economy were respectively tobacco industry with $1.07 \%$, special equipment industry with $0.59 \%$, nonferrous mining industry with $0.57 \%$, instrument industry with $0.46 \%$, and non-metal mining industry with $0.39 \%$; the five industry whose deduction of productivity resulted from scale efficiency were plastic making industry with 2.02 percentage points, paper making industry with $2.06 \%$, furniture industry with $2.60 \%$ percentage points, gas product and supply industry with $3.355 \%$, and timber industry with $3.53 \%$, respectively.

In general, the deduction of productivity owing to the scale dis-economy in China's industrial sector was $0.33 \%$ per year on average, which was insignificant compared 
with the influence of frontier technology progress and TE improvement on productivity. The effect of scale economy on productivity were respectively $-0.58,-0.63,-0.07$, $-0.04,0.06,-0.53$ and -0.52 during 1996-2002. However, on the micro level, there were some enterprises in certain industry with the potential of improving productivity by adjusting their scale. A thorough analysis of the factor allocation and scale economy on micro level will be presented in another article.

\section{Discussion}

Taking a comprehensive view of the five aspects analyzed above, the conclusion are drawn that along with the deepening of China's market-oriented economic reform and improvement of the economic environment, the total factor productivity of China's LMIE was growing continuously. Frontier technology progress was the main source of the productivity increase. However, the significant progress of production technology frontier consequently broadened the gap of technology efficiency between the frontier technology and the actual output. This gradually broadened efficiency gap between enterprises greatly obstructed the productivity rise of the whole industries. But it would be the potential driving force of productivity growth in the future. Using the stochastic frontier model for estimating the data of the LMIE during 1995-2002, these conclusions are made: (1) the weighted average of the annual growth of TFP was as high as $6.8 \%$ with a rising trend; (2) the contribution to TFP by frontier technology progress reached as much as $14 \%$ per year; (3) the broadened gap of technology efficiency (relative to frontier) between enterprises reduced the growth of TFP by $7.1 \%$ year on average; (4) Scale dis-economy slowed the growth of TFP by $0.33 \%$ per year on average;(5) AE contributed on average only $0.02 \%$ to the growth of TFP per year. The errors from the decomposition of TFP growth were less than $4 \%$ of the average TFP growth rate. A dynamic diagram is presented of the source of TFP growth in China's LMIE during 1996-2002 (Fig. 1).

For comparison, let the growth rate of TFP, FTP, change rate of TE, and contribution to TFP growth by AE and SE divided by the TFP annual average growth rate $6.8 \%$. The diagram clearly shows the great contribution to productivity growth by FTP and the negative effect on productivity growth due to the slow technical progress in the lagging enterprises. These two factors each have the magnitude that is equal to, or even more than the annual average growth rate of TFP. By comparison, in terms of magnitude the macro net effect on productivity growth of $\mathrm{AE}$ and $\mathrm{SE}$ was negligible.

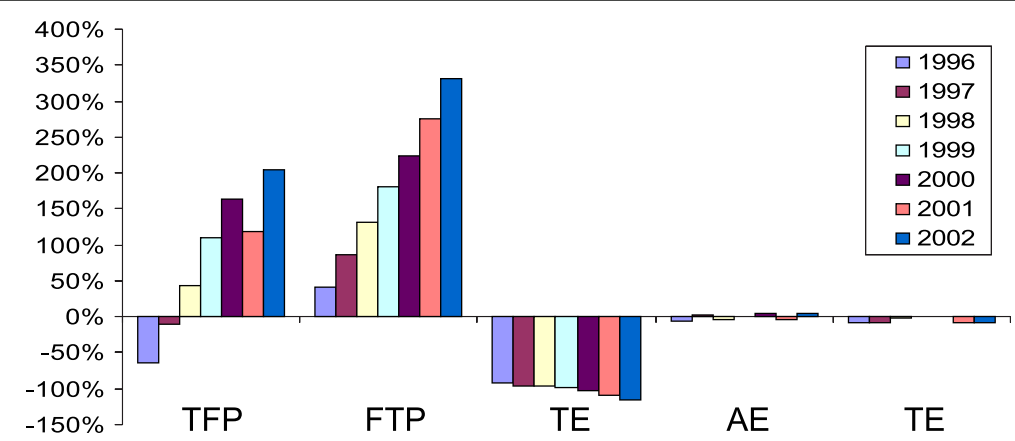

Fig. 1 Dynamic diagram of the source of TFP growth in China's LMIE during 1996-2002 (Unit: taking the average Annual TFP Growth during 1996-2002 as $100 \%)$ 


\section{Conclusions}

At the turn of the century, China has experienced an industrial productivity revolution mainly driven by the FTP. The FTP promoted the fast growth of industrial productivity on one hand and broadened the TE gap on the other hand, which means that the sustainable development of the economy and the industrial productivity revolution can be driven by both making industrial frontier technology progress and increasing industrial average efficiency. From the policy aspect, China's industrial development must place emphasis on enforcing competition, narrowing the efficiency gap between enterprises and keeping the frontier technology progressing by emulating, learning from, catching up with, helping each other, and at the same time absorbing advanced technology, and keeping the frontier technology progressing. In addition, it is necessary to further the market-orient economy reform, keeping the factor of labor and capital adjustable and increase the $\mathrm{AE}$ and $\mathrm{SE}$ of industrial economy on the micro level.

\section{Abbreviations}

AE: Allocative efficiency; FTP: Frontier technical progress; GDP: Gross Domestic Product; LMIE: Large and medium-sized industrial enterprises; LR: Likelihood ratio; NPL: Non-performing loan; OECD: Organization for Economic Co-operation and Development; SE: Scale economy; TE: Technical efficiency; TFP: Total factor productivity

\section{Acknowledgement}

This study has been sponsored by National Fund for Social Sciences (No. 16BJY062, 16ZD006) and New Century Talent Support Program of the Ministry of Education (NCET-10-0409).

\section{Authors' contributions}

TUZ designed the investigation, analyzed the data and draft the manuscript; SR helped collected data and revise the manuscript. Both authors read and approved the final manuscript.

\section{Competing interests}

The authors declare that they have no competing interest.

Received: 5 May 2016 Accepted: 21 August 2016

Published online: 28 November 2016

\section{References}

1. Aigner DJ, Lovell CAK, Schmidt J (1997) Formulation and estimation of stochastic frontier production function models. J Econ 6(1):21-37

2. Bauer PW (1990) Decomposing TFP growth in the presence of cost inefficiency, nonconstant returns to scale, and technological progress. J Prod Anal 1(4): 287-299

3. Fecher F, Perelman S (1992) Productivity growth and technical efficiency in OECD industrial activities. In: Caves RE, Bailey SD (ed) Industrial efficiency in six nations. The MIT Press, pp 459-488

4. Hu AG, Zheng JH (2004) Why the total factor productivity decreased obviously? China Economic Times

5. Jondrow J, Lovell CAK, Materov IS, Schmidt P (1982) On the estimation of technical inefficiency in the stochastic frontier production function model. J Econ 19(2-3):233-238

6. Kalirajan KP, Obwona MB, Zhao S (1996) A decomposition of total factor productivity growth: The case of Chinese agricultural growth before and after reforms. Am J Agric Econ 78(2):331-338

7. Kim SH, Han G (2001) A decomposition of total factor productivity growth in Korean manufacturing industry. J Prod Anal 16(3):269-281

8. Kim SH (2003) Identifying and estimating sources of technical inefficiency in Korean manufacturing industry. Contemp Econ Policy 21(1):132-144

9. Kumbhakar SC (2000) Estimation and decomposition of productivity change when production is not efficient: a panel data approach. Econ Rev 19(4):425-460

10. Kumbhakar SC, Lovell CAK (2000) Stochastic Frontier Analysis. Cambridge University Press, Cambridge

11. Meeusenm W, Broeck JVD (1977) Efficiency estimation from Cobb-Douglas producton functions with composed error. Int Econ Rev 18(18):435-444

12. Nishimizu M, Page JM (1982) Total factor productivity growth, technical progress and technical efficiency change: dimensions of productivity change in Yugoslavia, 1965-78. Econ J 92(368):929-936

13. Wei ZB, Varela O, Hassan MK (2002) Ownership and performance in Chinese manufacturing industry. J Multinational Financ Manag 12(1):61-78

14. Wu YR (2000) Is China's economic growth sustainable? A productivity analysis. China Econ Rev 11(3):278-296

15. Yao Y (1998) The influence of private-owned economic participants on our industrial TE. Econ Res 12:29-35

16. Yao Y, Zhang Q (2001) The TE analysis of Chinese industries. Econ Res 10:13-19 